\title{
Copeptin Level and Copeptin Response to Percutaneous Balloon Mitral Valvuloplasty in Mitral Stenosis
}

\author{
Özgür Günebakmaz ${ }^{a} \quad$ Ahmet Celik $^{b} \quad$ M. Tugrul Inanc ${ }^{c} \quad$ Mustafa Duran $^{d}$ \\ Ekrem Karakaya ${ }^{\text {e }}$ Murat Tulmac $^{f}$ Mahmut Akpek $^{c}$ Bahadir Sarli $^{d}$ Ali Ergin $^{c}$ \\ Ramazan Topsakalc \\ a Department of Cardiology, Kastamonu Munif Islamoglu State Hospital, Kastamonu, ${ }^{\mathrm{b}}$ Department of Cardiology, \\ Elazig Education and Research Hospital, Elazig, 'Department of Cardiology, Erciyes University School of Medicine, \\ ${ }^{d}$ Department of Cardiology, Kayseri Education and Research Hospital, Kayseri, e Department of Cardiology, Kirsehir \\ State Hospital, Kirsehir, and f Department of Cardiology, Kırıkkale University School of Medicine, Kırıkkale, Turkey
}

\section{Key Words}

Mitral stenosis • Percutaneous balloon mitral valvuloplasty • Copeptin

\begin{abstract}
We aimed to investigate copeptin levels in mitral stenosis (MS) patients and the behavior of copeptin after hemodynamic improvement achieved by percutaneous balloon mitral valvuloplasty (PBMV). The study involved 29 consecutive symptomatic patients with moderate to severe rheumatic MS who underwent PBMV. Twenty-eight age- and gendermatched healthy volunteers composed the control group. Blood samples for copeptin were obtained immediately before and $24 \mathrm{~h}$ after PBMV, centrifuged, then stored at $-70^{\circ} \mathrm{C}$ until assayed. The copeptin level of the patient group was statistically different from that of the control group (61.8 \pm 34.4 and $36.8 \pm 15.2 \mathrm{pg} / \mathrm{ml}$, respectively; $\mathrm{p}=0.001)$. PBMV resulted in a significant increase in mitral valve area and a significant decrease in transmitral gradient as well as systolic pulmonary artery pressure. While hemodynamic relief was
\end{abstract}

obtained, we detected a statistically significant decline in copeptin levels $24 \mathrm{~h}$ after PBMV compared to the baseline levels (from $61.8 \pm 34.4$ to $44.1 \pm 18.2 \mathrm{pg} / \mathrm{ml} ; \mathrm{p}=0.004$ ).

Copyright $\odot 2012$ S. Karger AG, Basel

\section{Introduction}

Rheumatic mitral stenosis (MS) is still a common disease in developing countries with high morbidity and mortality rates [1]. The treatment of choice for MS patients with favorable mitral valve morphology is percutaneous balloon mitral valvuloplasty (PBMV), first introduced in 1984 by the Japanese surgeon Inoue [2]. It is a safe and effective procedure with a high success rate and low morbidity [3]. After successful PBMV, early clinical and hemodynamic improvements are highly impressive and satisfactory for both clinicians and patients. While the mitral valve area increases, the left atrial pressure, mean transmitral gradient and pulmonary artery pressure decrease immediately.

\section{KARGER}

Fax +4161306 1234 E-Mail karger@karger.ch www.karger.com

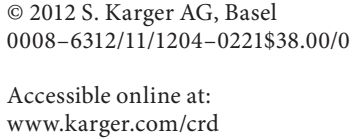


Arginine vasopressin (AVP), a vasoconstrictor and antidiuretic hormone, has well-established effects on osmoregulation and cardiovascular homeostasis [4]. Measurement of AVP levels is difficult because of its short half-life and unstable properties. Copeptin, the C-terminal part of preprovasopressin, is more stable and can be measured more easily and more accurately than AVP. It is cosecreted with AVP and thus directly associated with AVP production [5]. Recently, it has been confirmed that increased levels of copeptin are associated with a poor prognosis in heart failure patients. Compared to B-type natriuretic peptide (BNP) and the amino-terminal portion of proBNP (NT-proBNP), it is a more reliable outcome predictor in advanced heart failure [6].

No published data exist to date about the level of copeptin in patients with MS and the change in copeptin levels after PBMV. Thus, we aimed to investigate copeptin levels in MS patients and the behavior of copeptin after hemodynamic improvement achieved by PBMV.

\section{Methods}

\section{Study Population}

The study involved 29 consecutive symptomatic patients with moderate to severe rheumatic MS who underwent PBMV. The morphological features of the mitral valve were evaluated according to the scoring system described by Wilkins et al. [7]. If the score was $\leq 8$, it was considered suitable. Patients with moderate or severe mitral regurgitation and any moderate or severe valvular heart disease except MS were excluded from the study. Also, no patient had coronary artery disease, left ventricular systolic dysfunction, congenital heart disease or chronic kidney disease.

Twenty-eight age- and gender-matched healthy volunteers composed the control group.

The study was approved by the local ethics committee, and written informed consent was obtained from all patients enrolled in the study.

\section{Echocardiography}

Echocardiographic examination was carried out by a cardiology specialist at baseline and $24 \mathrm{~h}$ after PMBW, using Vivid 7 instruments (GE Medical Systems, Milwaukee, Wisc., USA), with a $2.5-\mathrm{MHz}$ transducer. All echocardiographic studies were performed according to the recommendations of the American Society of Echocardiography [8]. Transmitral gradients were measured by continuous-wave Doppler echocardiography in the apical four-chamber view. Mitral valve areas were calculated by a planimetric method and Doppler pressure half-time method. The sum of the transtricuspid gradient and right atrial pressure was noted as systolic pulmonary artery pressure (SPAP). We determined right atrial pressure according to Kircher et al. [9].

All patients underwent transesophageal echocardiography before PBMV to exclude the presence of left atrial thrombus.

\section{Cardiac Catheterization}

Standard right- and left-sided heart catheterization was performed using Philips Integris 5000 equipment (Philips Medical Systems, Best, The Netherlands). Invasive hemodynamic data were obtained before and immediately after PBMV. To evaluate mitral regurgitation, left ventriculography was performed before and after the procedure. Mitral regurgitation was classified according to Sellers et al. [10]. The mean transmitral gradient and SPAP were measured in all patients.

Percutaneous Balloon Mitral Valvuloplasty

An experienced cardiologist performed all PBMV procedures via an antegrade transvenous approach with a single-balloon stepwise dilatation technique using the Inoue balloon.

\section{Biochemical Analyses}

Blood samples for copeptin (ELISA Kit for Human Copeptin, Uscn Life Science Inc., Wuhan, China) were obtained immediately before and $24 \mathrm{~h}$ after PBMV, centrifuged, then stored at $-70^{\circ} \mathrm{C}$ until assayed. The detection limit of the assay was 7.4 $\mathrm{pg} / \mathrm{ml}$.

\section{Statistical Analyses}

Categorical variables are presented as counts and percentages and were compared using the $\chi^{2}$ test. Continuous variables are expressed as means and SD. Student's t test or the Mann-Whitney $\mathrm{U}$ test (as appropriate) was used for continuous variables. Invasive and echocardiographic data and copeptin levels obtained before and after PBMV were compared using Student's t test (paired, 2 -tailed). A 2 -sided $p$ value $<0.05$ was considered statistically significant. All statistical analyses were performed using the SPSS statistical package for Windows, version 13.0 (SPSS, Inc., Chicago, Ill., USA).

\section{Results}

Demographic characteristics as well as some baseline echocardiographic and laboratory variables of the patient group and control group are summarized in table 1 . Of the MS patients, 11 patients (38\%) were in New York Heart Association functional class 2 and 18 patients (62\%) were in class 3.

There were no significant differences between the two groups in terms of age, gender, body mass index, hemoglobin level, lipid profile, fasting blood glucose, left ventricular diameters, left ventricular ejection fraction, diabetes mellitus, hypertension and smoking. However, the copeptin level of the patient group was statistically different from that of the control group $(61.8 \pm 34.4$ and 36.8 $\pm 15.2 \mathrm{pg} / \mathrm{ml}$, respectively; $\mathrm{p}=0.001$; table 1 ).

PBMV led to a significant immediate increase in mitral valve area measured by both planimetric and pressure half-time methods, with a corresponding significant decrease in transmitral gradient and SPAP whether measured by catheter or by echocardiography. 
PBMV resulted in a significant increase in mitral valve area measured by both planimetric and pressure halftime methods (from $1.12 \pm 0.17$ to $1.76 \pm 0.41 \mathrm{~cm}^{2}, \mathrm{p}=$ 0.001 , and from $1.11 \pm 0.19$ to $1.82 \pm 0.32 \mathrm{~cm}^{2}, \mathrm{p}=0.001$, respectively; table 2 ; fig. 1 ).

On Doppler echocardiographic study, the transmitral gradient as well as SPAP decreased significantly $24 \mathrm{~h}$ after valvuloplasty (from $11.4 \pm 3.2$ to $5.9 \pm 2.3 \mathrm{~mm} \mathrm{Hg}, \mathrm{p}=$ 0.001 , and from $46.3 \pm 9.4$ to $35.7 \pm 9.1 \mathrm{~mm} \mathrm{Hg}, \mathrm{p}=$ 0.001 , respectively; table 2 ; fig. 1). Similarly, the same parameters measured by catheterization showed a sudden decrease immediately after the procedure (transmitral gradient from $14.9 \pm 5.6$ to $3.7 \pm 2.1 \mathrm{~mm} \mathrm{Hg}, \mathrm{p}=0.001$ SPAP from $51.4 \pm 11.9$ to $38.5 \pm 7.5 \mathrm{~mm} \mathrm{Hg}, \mathrm{p}=0.001$; table 2).

While hemodynamic relief was obtained, we detected a statistically significant decline in copeptin levels $24 \mathrm{~h}$ after PBMV compared to the baseline levels (from $61.8 \pm$ 34.4 to $44.1 \pm 18.2 \mathrm{pg} / \mathrm{ml}, \mathrm{p}=0.004$; table 2 ; fig. 1 ).

No patient had any thromboembolic event during or after the procedure. No urgent operation was required in any patient during or after the valvuloplasty procedure.

\section{Discussion}

The present study confirmed that the copeptin level in MS patients was higher than in the healthy subjects. In addition, this study suggested that PBMV reduced the copeptin level as well as the transmitral gradient and pulmonary hypertension. Thus, hemodynamic improvement in MS was associated with a decrease in the activity of the vasopressin system.

Rheumatic MS is still a major health problem in developing countries with high morbidity and mortality rates [1]. It is a progressive disease, which involves hemodynamic abnormalities as well as a rheumatic process $[11$, 12], causing progressive obstruction of the left ventricular inflow. When the valve area decreases to $<2 \mathrm{~cm}^{2}$, subjects usually develop exertional dyspnea as the initial symptom. Once this area decreases below $1.5 \mathrm{~cm}^{2}$, intervention is often necessary because of the intolerable symptoms or pulmonary hypertension, especially in patients with feasible valve morphology for PBMV [1]. Increased left atrial, pulmonary and right heart pressures and decreased cardiac output are the main hemodynamic disturbances encountered in MS.

PBMV, which is the treatment of choice in patients with pure MS with favorable mitral valve morphology, is
Table 1. Baseline characteristics, echocardiographic parameters and copeptin levels of patients and controls

\begin{tabular}{lccl}
\hline Baseline characteristics & $\begin{array}{c}\text { MS patients } \\
(\mathrm{n}=29)\end{array}$ & $\begin{array}{c}\text { Controls } \\
(\mathrm{n}=28)\end{array}$ & $\mathrm{p}$ \\
\hline Age, years & $44.4 \pm 12.3$ & $46.2 \pm 12.4$ & 0.58 \\
Male/female, $\mathrm{n}$ & $22 / 7$ & $22 / 6$ & 0.80 \\
BMI & $25.2 \pm 2.8$ & $24.8 \pm 2.5$ & 0.62 \\
Diabetes mellitus, $\mathrm{n}$ & $2(6.9)$ & $2(7.1)$ & 0.97 \\
Hypertension, $\mathrm{n}$ & $4(13.7)$ & $6(21.4)$ & 0.44 \\
Current smoker, $\mathrm{n}$ & $4(13.7)$ & $3(10.7)$ & 0.72 \\
Total cholesterol, mg/dl & $170.2 \pm 37.9$ & $181.2 \pm 42.6$ & 0.30 \\
LDL cholesterol, mg/dl & $109.9 \pm 32.4$ & $113.3 \pm 39.2$ & 0.71 \\
HDL cholesterol, mg/dl & $39.0 \pm 21.8$ & $34.5 \pm 8.9$ & 0.31 \\
Triglyceride, mg/dl & $136.3 \pm 97.1$ & $165.8 \pm 86.6$ & 0.23 \\
Na, mEq/l & $137.3 \pm 4.3$ & $139,7 \pm 6.5$ & 0.11 \\
K, mEq/l & $4.5 \pm 0.6$ & $4.4 \pm 0.6$ & 0.57 \\
Cl, mEq/l & $100.6 \pm 2.8$ & $100.5 \pm 3.2$ & 0.91 \\
Fasting glucose, mg/dl & $93.4 \pm 19.4$ & $99.3 \pm 16.3$ & 0.22 \\
Hemoglobin, g/dl & $13.4 \pm 1.8$ & $13.2 \pm 1.3$ & 0.55 \\
LVDD, cm & $4.7 \pm 0.4$ & $4.7 \pm 0.4$ & 0.96 \\
LVDS, cm & $3.0 \pm 0.4$ & $2.9 \pm 0.4$ & 0.46 \\
LVEF, \% & $62.8 \pm 6.7$ & $66.1 \pm 7.3$ & 0.08 \\
Copeptin, pg/ml & $61.8 \pm 34.4$ & $36.8 \pm 15.2$ & 0.001 \\
& & &
\end{tabular}

Data are presented as the mean values \pm SD or numbers of patients (percentage), as appropriate. $\mathrm{p}<0.05$ was considered statistically significant. BMI = Body mass index; LDL = low-density lipoprotein; $\mathrm{HDL}=$ high-density lipoprotein; $\mathrm{Na}=$ sodium; $\mathrm{K}=$ potassium; $\mathrm{Cl}$ = chloride; $\mathrm{LVDD}=$ left ventricular end-diastolic diameter; LVDS = left ventricular end-systolic diameter; LVEF = left ventricular ejection fraction.

Table 2. Echocardiograhic and hemodynamic characteristics and copeptin levels before and after PBMV in MS patients

\begin{tabular}{|c|c|c|c|}
\hline & Baseline & $\begin{array}{l}\text { One day } \\
\text { after } \\
\text { procedure }\end{array}$ & $\mathrm{p}$ \\
\hline MVA (planimetry), $\mathrm{cm}^{2}$ & $1.12 \pm 0.17$ & $1.76 \pm 0.41$ & 0.001 \\
\hline $\begin{array}{l}\text { MVA (pressure half-time), } \mathrm{cm}^{2} \\
\text { Transmitral MG (Doppler) }\end{array}$ & $1.11 \pm 0.19$ & $1.82 \pm 0.32$ & 0.001 \\
\hline mm Hg & $11.4 \pm 3.2$ & $3.7 \pm 2.1^{\mathrm{a}}$ & 0.001 \\
\hline $\begin{array}{l}\text { Transmitral MG (hemodynamic) } \\
\text { mm Hg }\end{array}$ & $14.9 \pm 5.6$ & $5.9 \pm 2.3$ & 0.001 \\
\hline SPAP (Doppler), mm Hg & $46.3 \pm 9.4$ & $35.7 \pm 9.1$ & 0.001 \\
\hline SPAP (hemodynamic), mm Hg & $51.4 \pm 11.9$ & $38.5 \pm 7.5^{\mathrm{a}}$ & 0.001 \\
\hline Copeptin, pg/ml & $61.8 \pm 34.4$ & $44.1 \pm 18.2$ & 0.004 \\
\hline
\end{tabular}

Data are presented as the mean values \pm SD. $\mathrm{p}<0.05$ was considered statistically significant. $\mathrm{MVA}=$ Mitral valve area; $\mathrm{MG}=$ mean gradient.

${ }^{\text {a }}$ Measured immediately at the end of the procedure. 
Fig. 1. Changes in echocardiographic parameters and copeptin levels after PBMV.
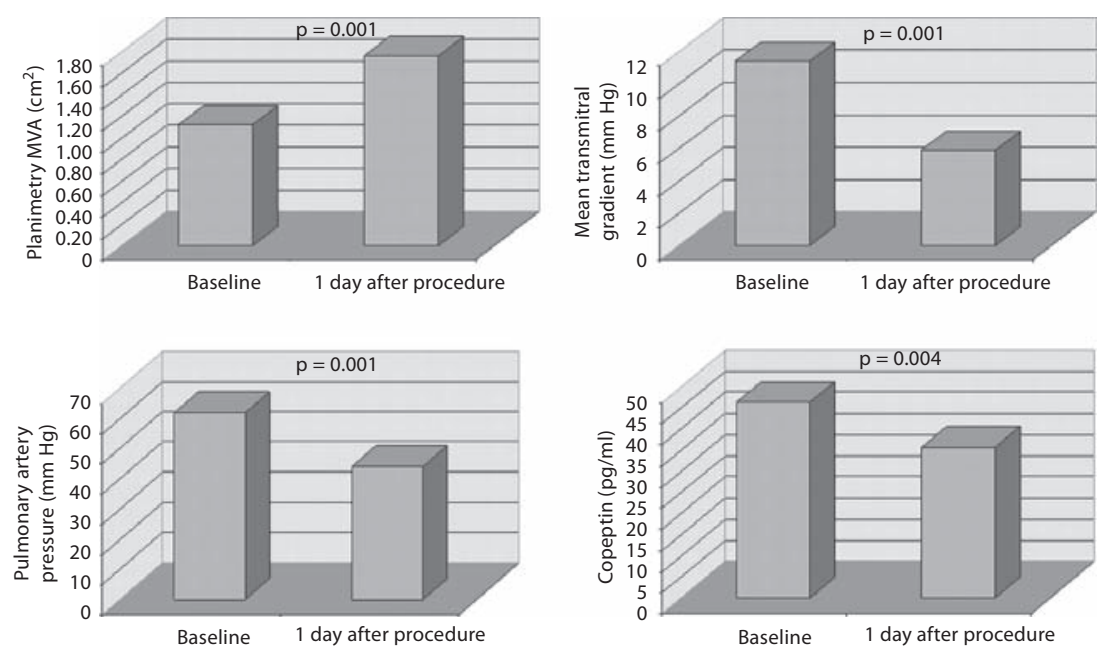

unique in that it provides dramatic hemodynamic and symptomatic relief as soon as it is carried out with success. Due to these sudden changes in hemodynamic and metabolic parameters in MS after PBMV, it has recently seemed to be highly attractive to investigate some characteristics of MS before and after the procedure. For instance, Cagli et al. [13] reported higher tumor necrosis factor- $\alpha$ and soluble tumor necrosis factor receptor levels in MS patients than in healthy control patients. They also showed that these markers reduced gradually at $24 \mathrm{~h}$ and at 4 weeks after PBMV. Logically, PBMV does not have any effect on inflammatory activity. Thus, they attributed this reduction in the above-mentioned inflammatory markers to the hemodynamic relief seen after PBMV.

Some researchers studying hemostatic parameters in MS showed that MS patients have a hypercoagulable state even in sinus rhythm $[14,15]$. In light of these data, Topaloglu et al. [16] evaluated soluble P-selectin (sP-selectin), which is one of the platelet activation markers, in MS patients. This molecule, a component of the membrane of the alpha and dense granules of platelets, is responsible for the adhesion of platelets to leukocytes or the endothelium. In this study, sP-selectin levels were found to be higher in MS patients than in the control group. In addition, it was demonstrated that $\mathrm{sP}$-selectin levels progressively declined at 24 hour and 4 weeks after PBMV.

NT-proBNP, which is secreted not only from ventricles but also atria [17], is a widely used diagnostic marker in congestive heart failure. It is also a prognostic pre- dictor of adverse cardiovascular events in congestive heart failure patients [18]. This peptide was studied by Iltumur et al. [19] in MS patients. They found a positive relationship between the NT-proBNP level and hemodynamic parameters in MS patients. In other words, a higher NT-proBNP level was associated with a higher transmitral gradient, higher SPAP and more severe MS. Both Chadha et al. [20] and Ramakrishnan et al. [21] confirmed that NT-proBNP levels decreased significantly $24 \mathrm{~h}$ after successful PBMV.

AVP is necessary to achieve and maintain normal osmotic and cardiovascular homeostasis. It stimulates free water reabsorption through the principal cells of the collecting ducts in the kidney. Its secretion is mainly regulated by the osmotic pressure of body fluids. Besides, acute changes in blood volume or pressure play an important role in AVP secretion. It also causes a procoagulant state by inducing platelet aggregation and the release of von Willebrand factor, P-selectin and factor VIII [22, 23]. Before AVP secretion, it is stored as a polypeptide precursor in the neurohypophysis. This preprovasopressin includes AVP, neurophysin and copeptin. So, if a stimulus for AVP secretion occurs, then both AVP and copeptin are released into the peripheral blood in equimolar amounts. That is, the copeptin level in peripheral blood closely reflects the AVP level. Because of the fact that vasopressin is unstable and largely (more than 90\%) attached to platelets, it is very difficult to measure vasopressin in peripheral blood. However, copeptin, the C-termi- 
nal part of the vasopressin prohormone, is measured easily and reliably [24]. So, nowadays, being able to measure the copeptin level simply and quickly encourages most clinicians to investigate the vasopressin system in various clinical conditions. For instance, copeptin was shown to be increased during acute exacerbation of chronic obstructive pulmonary disease [25]. In another study, Morgenthaler et al. [26] studied copeptin in hemorrhagic and septic shock patients. They noted higher copeptin levels in patients with hemorrhagic and septic shock than in the healthy subjects, and copeptin seemed to be a prognostic marker in sepsis. Enhörning et al. [27] carried out a study investigating copeptin in glucose metabolism. Interestingly, they found that copeptin predicted the development of diabetes mellitus regardless of diabetes risk factors at baseline [27]. Copeptin has also been studied in myocardial infarction and heart failure. Reichlin et al. [28] examined the value of copeptin to rapidly rule out acute myocardial infarction. They reported that copeptin combined with troponin appeared to be a good marker for rapidly ruling out acute myocardial infarction. Copeptin was also found to be an independent prognostic biomarker in ST elevation myocardial infarction and non-ST elevation myocardial infarction $[29,30]$. Neuhold et al. [6] assessed copeptin in chronic heart failure patients and reported that copeptin was superior to BNP and NT-proBNP for the prediction of all-cause mortality.

In the present study, we planned to evaluate the copeptin level in MS patients before and after PBMV for the first time. The background data encouraged us to carry out this study. These data are as follows: firstly, in congestive heart failure, vasopressin is released because of cardiac output failure [31,32]. Cardiac output failure leads to arterial underfilling and the stimulation of baroreceptors in the aortic arc and carotid sinus. This baroreceptor stimulation causes the release of vasopressin and of course copeptin. As in congestive heart failure patients, MS patients experience arterial underfilling not because of left ventricular systolic dysfunction but rather an increased transmitral gradient. Secondly, in chronic obstructive pulmonary disease, high vasopressin concentrations were detected because of the downregulation of vasopressin (V1) receptor caused by hypoxemia [33]. As in chronic obstructive pulmonary disease, pulmonary hypertension is usually present in MS because of the increased left atrial pressure, pulmonary arteriolar constriction and obliterative changes in the pulmonary vascular bed. Thirdly, Topaloglu et al. [16] found high sPselectin levels in MS patients. Also, it was shown that AVP caused P-selectin release. Therefore, we hypothesized that high sP-selectin levels in MS might result from increased AVP levels.

\section{Study Limitations}

This was a single-center study with a small patient sample size. We studied copeptin levels only $24 \mathrm{~h}$ after PBMV. The follow-up period was only 1 day. Therefore, we cannot make any conclusions regarding a relationship between symptomatic relief and the degree of copeptin decrease.

Further and larger studies are required to investigate the effect of the copeptin level on prognosis in MS patients. In addition, whether or not the copeptin level can be used as a marker combined with hemodynamic parameters in the decision-making process for PBMV or mitral valve replacement in MS patients necessitates further clinical trials.

\section{Conclusion}

Rheumatic MS patients have significantly higher copeptin levels compared to healthy control subjects. PBMV results in a dramatic decrease in copeptin levels which runs parallel with hemodynamic improvements.

\section{Conflict of Interest}

None.

References
Bonow RO, Carabello BA, Chatterjee K, de Leon AC Jr, Faxon DP, Freed MD, Gaasch WH, Lytle BW, Nishimura RA, O'Gara PT, O'Rourke RA, Otto CM, Shah PM, Shanewise JS; 2006 Writing Committee Members; American College of Cardiology/American Heart Association Task Force: 2008 focused update incorporated into the ACC/AHA 2006 guidelines for the management of patients with valvular heart disease: a report of the American College of Cardiology/American Heart Association Task Force on Practice Guidelines (Writing Committee to Revise the 1998 Guidelines for the Management of Patients With Valvular Heart Disease): endorsed by the Society of Cardiovascular Anesthesiologists, Society for Cardiovascular Angiography and Interventions, and Society of Thoracic Surgeons. Circulation 2008;118:e523-e661. 
-2 Inoue K, Owaki T, Nakamura T, Kitamura F, Miyamoto N: Clinical application of transvenous mitral commissurotomy by a new balloon catheter. J Thorac Cardiovasc Surg 1984;87:394-402.

- 3 Nobuyoshi M, Arita T, Shirai S, Hamasaki $\mathrm{N}$, Yokoi $\mathrm{H}$, Iwabuchi $\mathrm{M}$, Yasumoto $\mathrm{H}$, Nosaka H: Percutaneous balloon mitral valvuloplasty: a review. Circulation 2009;119: 211-219.

4 Itoi K, Jiang YQ, Iwasaki Y, Watson SJ: Regulatory mechanisms of corticotropin-releasing hormone and vasopressin gene expression in the hypothalamus. J Neuroendocrinol 2004; 16:348-355.

-5 Struck J, Morgenthaler NG, Bergmann A: Copeptin, a stable peptide derived from the precursor, is elevated in serum of sepsis patients. Peptides 2005;26:2500-2504.

-6 Neuhold S, Huelsmann M, Strunk G, Stoiser B, Struck J, Morgenthaler NG, Bergmann A, Moertl D, Berger R, Pacher R: Comparison of copeptin, B-type natriuretic peptide, and amino-terminal pro-B-type natriuretic peptide in patients with chronic heart failure: prediction of death at different stages of the disease. J Am Coll Cardiol 2008;52:266-272.

7 Wilkins GT, Weyman AE, Abascal VM, Block PC, Palacios IF: Percutaneous balloon dilatation of the mitral valve: an analysis of echocardiographic variables related to outcome and the mechanism of dilatation. $\mathrm{Br}$ Heart J 1988;60:299-308.

-8 Quinones MA, Otto CM, Stoddard M, Waggoner A, Zoghbi WA: Doppler Quantification Task Force of the Nomenclature and Standards Committee of the American Society of Echocardiography. Recommendations for quantification of Doppler echocardiography: a report from the Doppler Quantification Task Force of the Nomenclature and Standards Committee of the American Society of Echocardiography. J Am Soc Echocardiogr 2002;15:167-184.

-9 Kircher BJ, Himelman RB, Schiller NB: Noninvasive estimation of right atrial pressure from the inspiratory collapse of the inferior vena cava. Am J Cardiol 1990;66:493-496.

-10 Sellers RD, Levy MJ, Amplatz K, Lillehei CW: Left retrograde cardioangiography in acquired cardiac disease: technic, indications and interpretations in 700 cases. Am J Cardiol 1964;14:437-447.

-11 Narin N, Kütükçüler N, Ozyürek R, Bakiler AR, Parlar A, Arcasoy M: Lymphocyte subsets and plasma IL-1 alpha, IL-2, and TNFalpha concentrations in acute rheumatic fever and chronic rheumatic heart disease. Clin Immunol Immunopathol 1995;77:172176.

12 Morris K, Mohan C, Wahi PL, Anand IS, Ganguly NK: Enhancement of IL-1, IL-2 production and IL-2 receptor generation in patients with acute rheumatic fever and active rheumatic heart disease; a prospective study. Clin Exp Immunol 1993;91:429-436.
3 Cagli KE, Aras D, Topaloglu S, Geyik B, Ayaz S, Cagirci G, Kisacik HL, Korkmaz S: Plasma levels of tumor necrosis factor-alpha and its receptors in patients with mitral stenosis and sinus rhythm undergoing percutaneous balloon valvuloplasty. Heart Vessels 2010;25: 131-137.

14 Ileri M, Büyükaşik Y, Ileri NS, Haznedaroglu IC, Göksel S, Kirazli S, Dündar S: Activation of blood coagulation in patients with mitral stenosis and sinus rhythm. Am J Cardiol 1998;81:795-797.

15 Marín F, Roldán V, Monmeneu JV, Bodí V, Fernández C, de Burgos FG, Marco P, Sogorb F: Prothrombotic state and elevated levels of plasminogen activator inhibitor-1 in mitral stenosis with and without atrial fibrillation. Am J Cardiol 1999;84:862-864

16 Topaloglu S, Aras D, Ergun K, Geyik B, Ayaz S, Cay S, Cagirci G, Tufekcioglu O, Korkmaz S: Plasma level of soluble P-selectin in patients with rheumatic mitral stenosis and sinus rhythm undergoing percutaneous mitral balloon valvuloplasty. J Thromb Thrombolysis 2007;23:199-204.

17 Goetze JP, Friis-Hansen L, Rehfeld JF, Nilsson B, Svendsen JH: Atrial secretion of Btype natriuretic peptide. Eur Heart J 2006; 27:1648-1650.

18 Tsutamoto T, Wada A, Maeda K, Hisanaga T, Mabuchi N, Hayashi M, Ohnishi M, Sawaki M, Fujii M, Horie H, Sugimoto Y, Kinoshita M: Plasma brain natriuretic peptide level as a biochemical marker of morbidity and mortality in patients with asymptomatic or minimally symptomatic left ventricular dysfunction. Comparison with plasma angiotensin II and endothelin-1. Eur Heart J 1999; 20:1799-1807.

19 Iltumur K, Karabulut A, Yokus B, Yavuzkir M, Taskesen T, Toprak N: N-terminal proBNP plasma levels correlate with severity of mitral stenosis. J Heart Valve Dis 2005; 14 : 735-741.

20 Chadha DS, Karthikeyan G, Goel K, Malani SK, Seth S, Singh S, Dhall A, Bhargava B: Nterminal pro-BNP plasma levels before and after percutaneous transvenous mitral commissurotomy for mitral stenosis. Int J Cardiol 2010;144:238-240.

21 Ramakrishnan S, Agarwal A, Singh S, Karthikeyan G, Seth S, Narang R, Bhargava B: NT-pro-BNP levels as a marker of success of percutaneous transvenous mitral commissurotomy. Indian Heart J 2010;62:35-38.

22 Katan M, Muller B, Christ-Crain M: Copeptin: a new and promising diagnostic and prognostic marker. Crit Care 2008;12:117.
23 Jarai R, Mahla E, Perkmann T, Jarai R, Archan S, Tentzeris I, Huber K, Metzler H: Usefulness of pre-operative copeptin concentrations to predict post-operative outcome after major vascular surgery. Am J Cardiol 2011; 108:1188-1195.

24 Morgenthaler NG, Struck J, Alonso C, Bergmann A: Assay for the measurement of copeptin, a stable peptide derived from the precursor of vasopressin. Clin Chem 2006;52: 112-119.

25 Antonescu-Turcu AL, Tomic R: C-reactive protein and copeptin: prognostic predictors in chronic obstructive pulmonary disease exacerbations. Curr Opin Pulm Med 2009; 15:120-125.

26 Morgenthaler NG, Müller B, Struck J, Bergmann A, Redl H, Christ-Crain M: Copeptin, a stable peptide of the arginine vasopressin precursor, is elevated in hemorrhagic and septic shock. Shock 2007;28:219-226.

27 Enhörning S, Wang TJ, Nilsson PM, Almgren P, Hedblad B, Berglund G, Struck J, Morgenthaler NG, Bergmann A, Lindholm E, Groop L, Lyssenko V, Orho-Melander M, NewtonCheh C, Melander O: Plasma copeptin and the risk of diabetes mellitus. Circulation 2010;121:2102-2108.

28 Reichlin T, Hochholzer W, Stelzig C, Laule $\mathrm{K}$, Freidank $\mathrm{H}$, Morgenthaler NG, Bergmann A, Potocki M, Noveanu M, Breidthardt T, Christ A, Boldanova T, Merki R, Schaub N, Bingisser R, Christ M, Mueller C: Incremental value of copeptin for rapid rule out of acute myocardial infarction. J Am Coll Cardiol 2009;54:60-68.

29 Khan SQ, Dhillon OS, O’Brien RJ, Struck J, Quinn PA, Morgenthaler NG, Squire IB, Davies JE, Bergmann A, Ng LL: C-terminal provasopressin (copeptin) as a novel and prognostic marker in acute myocardial infarction: Leicester Acute Myocardial Infarction Peptide (LAMP) study. Circulation 2007; 115:2103-2110.

-30 Narayan H, Dhillon OS, Quinn PA, Struck J, Squire IB, Davies JE, Ng LL: C-terminal provasopressin (copeptin) as a prognostic marker after acute non-ST elevation myocardial infarction: Leicester Acute Myocardial Infarction Peptide II (LAMP II) study. Clin Sci (Lond) 2011;121:79-89.

31 Oghlakian G, Klapholz M: Vasopressin and vasopressin receptor antagonists in heart failure. Cardiol Rev 2009;17:10-15.

- 32 Lee CR, Watkins ML, Patterson JH, Gattis W, O'connor CM, Gheorghiade M, Adams KF Jr: Vasopressin: a new target for the treatment of heart failure. Am Heart J 2003;146: 9-18.

- 33 Jin HK, Yang RH, Chen YF, Thornton RM, Jackson RM, Oparil S: Hemodynamic effects of arginine vasopressin in rats adapted to chronic hypoxia. J Appl Physiol 1989;66:151160. 